\title{
Formação da veia jugular externa no veado catingueiro (Mazama gouazoubira)
}

\author{
Gregório Corrêa Guimarães ${ }^{1}$ \\ Matheus Camargos de Britto Rosa ${ }^{1}$ \\ Gabriela Castro Lopes ${ }^{1}$ \\ Thiago Páscoa Narciso ${ }^{1}$ \\ Fabrício Singaretti de Oliveira ${ }^{2 *}$ \\ ${ }^{1}$ Departamento de Medicina Veterinária, Universidade Federal de Lavras \\ Caixa Postal 3037, CEP 37200-000, Lavras - MG, Brasil \\ ${ }^{2}$ Departamento de Medicina Veterinária, Universidade Estadual de Maringá, Campus Umuarama \\ Caixa Postal 65, CEP 87501-970, Umuarama - PR, Brasil. \\ *Autor para correspondência \\ singaretti@ig.com.br
}

\section{Resumo}

O veado catingueiro (Mazama gouazoubira) é um ruminante silvestre de pelagem curta, marrom-acizentada, que vive nas Américas Central e do Sul. Objetivou-se descrever a formação da veia jugular externa em um exemplar macho que foi a óbito por atropelamento. As regiões da face e cervical foram dissecadas de modo a possibilitar a visualização da veia jugular externa e suas tributárias. Esta se formou a partir da união das veias maxilar e linguofacial. A primeira originou-se das veias temporal superficial e transversa da face, que em seu percurso recebeu as veias angular do olho, dorsal e lateral do nariz e labial superior. A segunda formou-se após a anastomose das veias lingual e facial. A veia facial originou-se da união das veias labial inferior e profunda da face, no terço médio da face, rostralmente ao músculo masseter. Esse arranjo vascular difere daquele comumente observado em ruminantes domésticos, nos quais a veia transversa da face se mostra pouco desenvolvida e a facial recebe as veias angular do olho, dorsais e lateral do nariz, além da labial superior. A veia jugular externa do veado catingueiro apresentou as mesmas tributárias que os ruminantes domésticos, porém, com arranjo vascular das veias facial e transversa da face de forma diferente.

Palavras-chave: Face; Jugular externa; Tributárias; Veado catingueiro

\section{Abstract}

Formation of the external jugular vein in the brown brocket deer (Mazama gouazoubira). The brown brocket deer (Mazama gouazoubira) is a brown-greyish short-haired wild ruminant living in Central and South Americas. This paper aimed at describing the formation of the external jugular vein in a male specimen which died due to run-over. The facial and cervical regions were dissected so as to allow the visualization of the external jugular vein and its tributaries. This vein was formed by the union of the maxillary and linguofacial veins. The first originated from the superficial and transverse facial temporal veins, and it received along its 
length the angular vein of the eye, as well as the dorsal and lateral veins of the nose and upper lip. The second was formed after the anastomosis of the lingual and facial veins. The facial vein was originated by the union of the lower lip and deep facial veins, in the middle third of the face, rostral to the masseter muscle. This vascular arrangement differs from that usually observed in domestic ruminants, in which the transverse facial vein is underdeveloped and the facial vein receives the angular vein of the eye, the dorsal and lateral veins of the nose, besides the upper lip vein. The external jugular vein in the brown brocket deer presented the same tributaries than domestic ruminants, however, with a different vessel arrangement of the facial and facial transverse veins.

Key words: External jugular; Face; Brown brocket deer; Tributaries

\section{Introdução}

O veado catingueiro (Mazama gouazoubira) é encontrado nas Américas do Sul e Central (REIS et al., 2005), ocorrendo em todo território brasileiro (SANTOS, 1984; BECKER; DALPONTE, 1999), habitando caatingas e matas ralas. Possui porte médio, com comprimento em torno de $100 \mathrm{~cm}$ (SANTOS, 1984) e apresenta pelagem curta com coloração marromacizentada. As regiões ventrais do tronco, cauda e faríngea são brancas, apresentando ainda uma mancha supra-orbital, que às vezes forma um anel perioftálmico (REIS et al., 2005).

É uma espécie selvagem que tem demonstrado grande interesse científico recente, como em pesquisas envolvendo anestesia, utilizando a exteriorização da artéria carótida comum externa (MUNERATO et al., 2001), e na área de morfologia envolvendo a topografia da medula espinhal (LIMA et al., 2010), a irrigação arterial do baço (MELO et al., 2011) e histomorfometria testicular (COSTA et al., 2011).

A veia jugular externa representa o principal vaso de drenagem da cabeça, e se forma nos ruminantes domésticos a partir da união das veias maxilar e linguofacial (GODINHO et al., 2001). Tanto a veia jugular externa quanto as demais veias que drenam a face foram descritas em animais domésticos (SCHWARZE; SCHRÖDER, 1972; DYCE et al., 2010; KÖNIG; LIEBICH, 2011). Ela destaca-se na prática da Medicina Veterinária pelo fato de ser o local de eleição para injeções intravenosas nas espécies domésticas de grande porte (DYCE et al., 2010).

O objetivo desse trabalho foi descrever a formação da veia jugular externa no veado catingueiro, buscandose evidenciar semelhanças e diferenças em relação às outras espécies de ruminantes, contribuindo dessa forma com a anatomia descritiva e comparada.

\section{Materiais e Métodos}

Foi utilizado um exemplar de veado catingueiro macho, que veio a óbito após atropelamento em rodovia do estado de Minas Gerais e que foi resgatado por pesquisadores do projeto "Corredores naturais - entendendo os efeitos de estradas nos processos de fragmentação e conectividade - CRA-APQ-02805-09/FAPEMIG" e transportado para o Laboratório de Anatomia Animal da Universidade Federal de Lavras, MG.

Por meio de injeções intramusculares e intraviscerais, o animal foi fixado em solução aquosa de formaldeído a $10 \%$, mantido na mesma solução por pelo menos $96 \mathrm{~h}$, e então lavado em água corrente para posterior dissecação e fotodocumentação.

A dissecação dos vasos da face e da região cervical foi realizada com instrumental cirúrgico como pinças anatômicas com e sem dente, pinças histológicas, tesouras, bisturis. Contou-se ainda com o auxílio de uma lupa Dekel ${ }^{\circledR}$ modelo TL-1120. A nomenclatura adotada neste trabalho está de acordo com o Nomenclatura Anatômica Veterinária (SCHALLER, 1999).

\section{Resultados}

A veia jugular externa formou-se a partir da união das veias maxilar e linguofacial. A veia maxilar originou-se da confluência das veias temporal superficial e transversa da face, a qual recebeu as veias tributárias angular do olho, dorsais do nariz, lateral do nariz e veia labial superior. 
A veia linguofacial se formou a partir da anastomose das veias lingual e facial. Esta apresentou trajeto curto e originou-se a partir da convergência das veias labial inferior e profunda da face, logo rostralmente ao músculo masseter e aproximadamente no terço médio da face (Figura 1).

FIGURA 1: Desenho esquemático da drenagem venosa na face do veado catingueiro. Evidenciam-se as veias angular do olho (1), dorsais do nariz (2), lateral do nariz (3), labial superior (4), transversa da face (5), labial inferior (6), profunda da face (7), facial (8), lingual (9), linguofacial (10), temporal superficial (11), maxilar (12) e jugular externa (13).

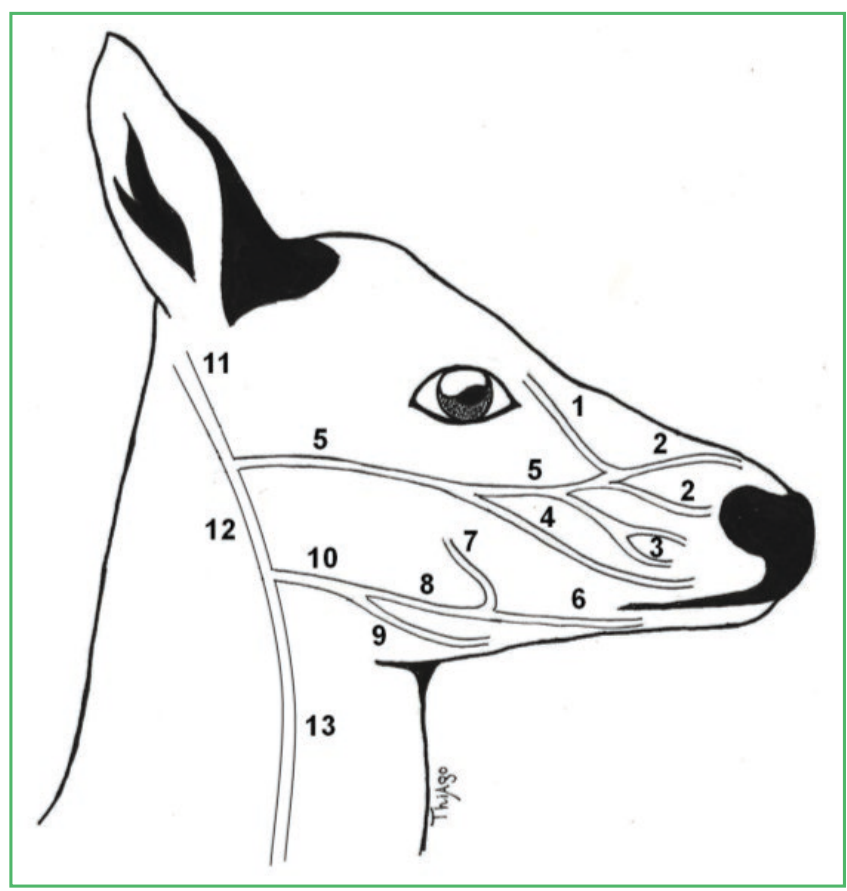

\section{Discussão}

No veado catingueiro, observou-se a formação da veia jugular externa a partir da anastomose das veias linguofacial e maxilar, assim como é relatado para as espécies domésticas (SCHWARZE; SCHRÖDER, 1972; DYCE et al., 2010; KÖNIG; LIEBICH, 2011), porém suas tributárias exibiram um padrão distinto do que ocorre normalmente em ruminantes domésticos, conforme descrições de Godinho et al. (2001).

A veia facial originou-se após a união das veias labial inferior e profunda da face, aproximadamente no terço médio da margem rostral do músculo masseter, diferentemente do observado em ruminantes domésticos, nos quais se observa uma pequena e pouco desenvolvida veia transversa da face junto à lateral do músculo masseter (SCHWARZE; SCHRÖDER, 1972; DYCE et al., 2010; KONIG; LIEBICH, 2011).

Notou-se também que, no veado catingueiro, a veia transversa da face apresenta-se bem desenvolvida, e sua formação ocorre a partir da anastomose das veias angular do olho, dorsal do nariz, lateral do nariz e labial superior. A veia transversa da face participa da formação da veia maxilar. Este arranjo vascular difere daquele comumente observado em ruminantes e demais animais domésticos, onde a veia transversa da face se mostra pouco desenvolvida e a facial recebendo as veias angular do olho, dorsais e lateral do nariz, além da labial superior (SCHWARZE; SCHRÖDER, 1972; DYCE et al., 2010; KONIG; LIEBICH, 2011).

Embora se tenha utilizado apenas um exemplar de veado catingueiro, foi evidente que a veia jugular externa estudada exibiu as mesmas tributárias, porém com arranjo vascular das veias facial e transversa da face de forma diferente dos ruminantes domésticos.

\section{Referências}

BECKER, M.; DALPONTE, J. C. Rastros de mamíferos silvestres brasileiros. 2. ed. Brasília: Editora UNB, 1999. p. 122-123.

COSTA, K. L. C.; MATTA, S. L. P.; GOMES, M. L. M.; PAULA, T. A. R; FREITAS, K. M.; CARVALHO, F. A. R.; SILVEIRA, J. A.; DOLDERB, H.; MENDIS-HANDAGAMAD, S. M. L. C. Histomorphometric evaluation of the neotropical brown brocket deer Mazama gouazoubira testis, with an emphasis on cell population indexes of spermatogenic yield. Animal Reproduction Science, Amsterdam, v. 127, n. 3-4, p. 202-212, 2011.

DYCE, K. M.; SACK, W. O.; WENSING, C. J. G. Tratado de anatomia veterinária. 4. ed. Rio de Janeiro: Elsevier, 2010. 834 p. GODINHO, H. P.; CARDOSO, F. M.; CASTRO, A. C. S. Anatomia dos ruminantes domésticos. Belo Horizonte: Universidade Federal de Minas Gerais, 2001. 435 p

KÖNIG, H. E.; LIEBICH, H. G. Anatomia dos animais domésticos - Texto e atlas colorido. 4. ed. Porto Alegre: Artmed, 2011. 787 p.

LIMA, F. C.; SANTOS, A. L. Q.; LIMA, B. C.; VIEIRA, L. G.; HIRANO, L. Q. L. Topographic anatomy of the spinal cord and vertebromedullary relationships in Mazama gouazoubira Fisher, 1814 (Artiodactyla; Cervidae). Acta Scientiarum, Biological Sciences, Maringá, v. 32, n. 2, p. 189-194, 2010.

MELO, A. P. F.; SOUZA, W. M.; RODRIGUES, R. F.; ALVES, F. R.; RICI, R. E. G.; GUERRA, R. R.; FAVARON, P. O.; MIGLINO, M. A.; DI DIO, L. J. A. Anatomical description of arterial segments 
of the spleen of deer. Anatomia, Histologia, Embryologia, Berlin, v. 40, n. 4, p. 243-248, 2011. Article first published online: 22 MAR 2011. DOI: 10.1111/j.1439-0264.2011.01063.x

MUNERATO, M. S.; DUARTE, J. M. B.; MARQUES, J. M. A. Carotid artery exteriorization in brown brocket deer (Mazama gouazoubira) for an experimental study of anesthesia. Journal of Zoo and Wildlife Medicine, Yulee, v. 40, n. 3, p. 474-477, 2009.

REIS, N. R.; PERACCHI, A. L.; MARIÑO, H. F.; ROCHA, V. J. Mamíferos da Fazenda Monte Alegre - Paraná. Londrina: Eduel, 2005. 224 p.
SANTOS, E. Entre o gambá e o macaco. v. 6. Belo Horizonte: Itatiaia, 1984. $287 \mathrm{p}$.

SCHALLER, O. Nomenclatura anatômica veterinária ilustrada. São Paulo: Manole, 1999. 614 p.

SCHWARZE, E.; SCHRÖDER, L. Compendio de anatomía veterinária. Zaragoza: Acribia, 1972. 247 p. 